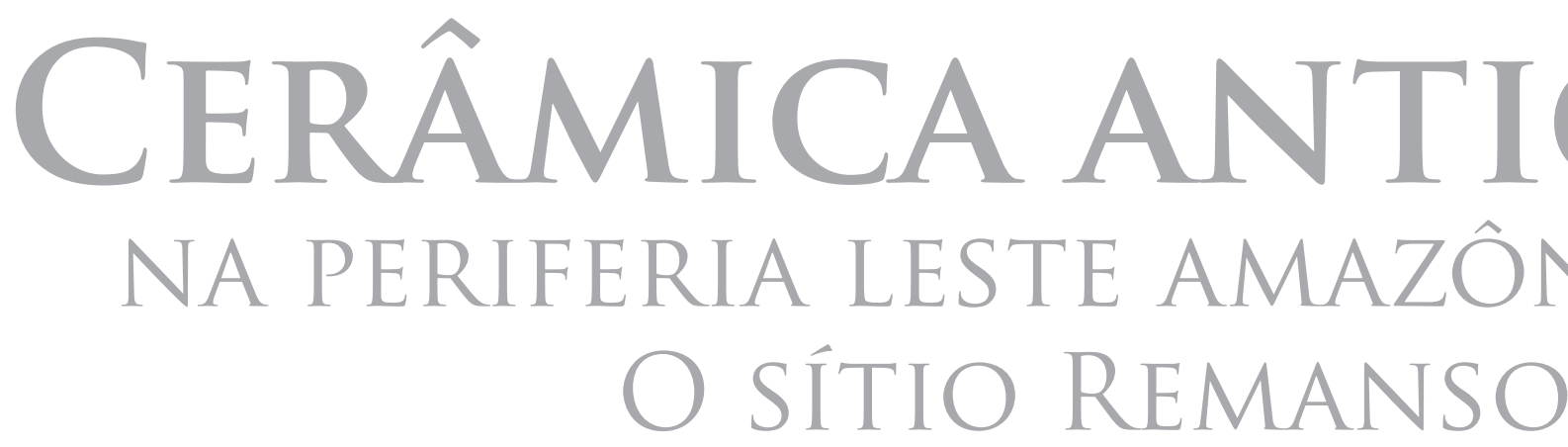




\section{CERÂMICA ANTIGA NA PERIFERIA LESTE AMAZÔNICA: \\ O SÍTIO REMANSO/MA}

\section{FERNANDO OZORIO DE A LMEIDA}




\title{
CERÂMICA ANTIGA NA PERIFERIA LESTE AMAZÔNICA: O SÍTIO REMANSO/MA
}

\section{Resumo}

O interior do Estado do Maranhão é uma das regiões menos conhecidas na Arqueologia da América do Sul. É nesse contexto obscuro que se encontra o sítio Remanso, onde foi identificada uma cerâmica incisa e modelada, com datas desde 1600 a.C.. Propõe-se, com base na análise do material cerâmico e da cronologia desse sítio, contribuir para a discussão das antigas ocupações de grupos ceramistas no leste sul-americano.

Palavras-chave: Arqueologia Amazônica, cerâmica incisa e modelada, transmissão estilística

\section{EARLY POTTERY IN THE EASTERN AMAZONIAN PERIPHERY: THE REMANSO SITE/MA}

\begin{abstract}
The interior of the Brazilian State of Maranhão is one of least known archaeological regions in South America. It is in this obscure context that lays the Remanso site, where an incised modeled pottery was found, with dates stretching back to 1600 B.C. Supported by an analysis of pottery and chronology, my aim is to contribute to the debate on ancient ceramic occupations in eastern South America.
\end{abstract}

Key words: Amazonian archaeology, incised modeled pottery, transmission of style

\section{CERÁMICA ANTIGUA EN LA PERIFERIA DEL ESTE AMAZÓNICO: EL SITIO REMANSO/MA}

\section{Resumen}

El interior del Estado de Maranhão es una de las regiones menos conocidas en la arqueología de América del Sur. Es en este contexto obscuro que se encuentra el sitio Remanso, donde fue identificada una cerámica incisa y modelada con fechas que alcanzan 1600 a.C. Se intenta, basado en el análisis del material cerámico y de la cronología de este sitio, contribuir para la discusión sobre las antiguas ocupaciones de grupos ceramistas en el este sudamericano.

Palabras clave: Arqueología Amazónica, cerámica incisa y modelada, transmisión estilística

Endereço para correspondência: ARQUEOTROP - Laboratório de Arqueologia dos Trópicos. Museu de Arqueologia e Etnologia, Universidade de São Paulo. Av. Almeida Prado, 1466, Cidade Universitária, São Paulo-SP, CEP. 05508-070. E-mail: fernandozorio@usp.br 


\section{INTRODUÇÃO}

No presente artigo busca-se contribuir para a compreensão das antigas cerâmicas incisas e modeladas da Amazônia. O foco do estudo será o sítio Remanso, localizado no interior maranhense, e possuidor de cerâmica que data de pelo menos 1600 a.C. (Figura 1). Pretende-se compreender os processos de manutenção tecnológica e estilística por parte do grupo que fabricou vasos cerâmicos de forma extremamente homogênea através do tempo.

O interior do Estado do Maranhão é uma das regiões mais pobres do Brasil e sua arqueologia é pouco conhecida. Pode-se dizer que essa região possui uma vegetação de floresta estacionária perene, uma de transição entre a floresta tropical amazônica e uma vegetação aberta de cerrado. Há um grande número de rios que correm em geral de sudoeste para nordeste, desaguando no oceano Atlântico. Entre esses rios é possível destacar, pelo volume e extensão, o Pindaré, o Grajaú, o Itapecurú e o Mearim. É na margem esquerda do rio Mearim, no topo de uma pequena

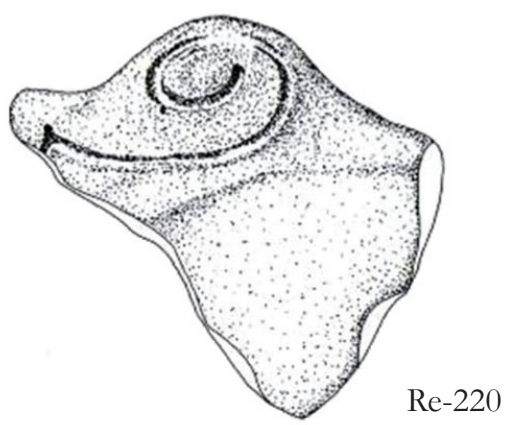

Figura 1 - Borda modelada com decoração incisa do sítio Remanso (MA). colina, que se encontra o sítio Remanso, foco do presente estudo.

Dados etnográficos (Nimuendajú 1946, 1967; Ribeiro 2006; Huxley 1956; Wagley \& Galvão 1961; Balée 1994) e etnohistóricos (Abbeville 1975 [1614]; Coelho 1990; Évreux 2002 [1614]) indicam que essa região era habitada predominantemente por grupos falantes da família Tupi-Guarani e de grupos Jê-Timbira na época do contato.

Ao analisar doze sítios arqueológicos das bacias dos rios Tocantins e Itapecurú (Scientia 2008) foi possível distinguir, ainda que de maneira grosseira, esses dois grupos, representados arqueologicamente por cerâmica pintada, corrugada, com antiplástico mineral (Tupi-Guarani), e outra fina, simples, com antiplástico de caraipé (Jê-Timbira). Apenas um sítio não foi encaixado nesse duo: o sítio Remanso. Este possuía cerâmica temperada com argila moída e decoração plástica rica em motivos incisos e apliques modelados. As formas não eram tão complexas quanto as formas da Subtradição Tupinambá Amazônica (ligada aos falantes do grupo Tupi-Guarani), nem tão simples quanto o segundo agrupamento cerâmico (aparentemente ligado a um contexto Jê-Timbira). Por fim, enquanto os sítios com cerâmica Tupinambá possuíam uma cronologia datada com segurança entre 700-1600 d.C. (Almeida 2008), e o segundo agrupamento possuía apenas uma data em 1000 d.C. (Scientia 2008), o sítio Remanso possuía datas antigas, atingindo 1600 a.C. (ou mais, já que as datas mais antigas não foram incluídas). Além do mais, há indícios de que o sítio Remanso não é apenas um sítio antigo como, pos- 
sivelmente, um sítio ocupado (e reocupado) por centenas de anos por um grupo com uma mesma indústria cerâmica. Assim, se a proposta geral desse artigo é inserir o sítio Remanso no contexto das antigas cerâmicas do leste da América do Sul, há também a proposta especifica de tentar compreender a manutenção das escolhas feitas para a manufatura de objetos cerâmicos durante os longos períodos em que o sítio parece ter sido ocupado.

\section{CARACTERÍSTICAS DO SÍTIO REMANSO}

O sítio Remanso foi encontrado nos arredores do município de Esperantinópolis, sob as coordenadas UTM 23M 523310E 9455830N (Figura 2). Ele foi delimitado através da execução de uma malha de unidades de $1 \mathrm{~m}^{2}$, espaçadas em 50 × $50 \mathrm{~m}$, e escavadas em níveis artificiais de $10 \mathrm{~cm}$. Um total de 103 unidades foi executado para a delimitação do sítio, 68 com material arqueológico. A área do sítio foi estimada em 230 mil metros quadrados. Foram abertas também cinco áreas de escavação, medindo $3 \times 3$ metros cada. O material lítico e cerâmico foi geralmente encontrado entre os níveis $20 \mathrm{~cm}$ e $70 \mathrm{~cm}$. Em algumas unidades foi encontrado material lítico em níveis mais profundos (Scientia 2008).

De maneira geral, o mapa de dispersão do material cerâmico (Figura 3) indica uma distribuição randômica, com uma pequena exceção de dois níveis $(10-20 \mathrm{~cm}$ e 40-50 m), que estão menos distantes de apontar para uma disposição circular.

Apesar da semelhança tecnológica entre o material lítico encontrado junto com a cerâmica e o encontrado sem cerâmica optou-se por uma postura analítica conservadora. Isto é, o sítio permaneceu sendo considerado como possuidor de ocupações distintas de um grupo lítico e outro grupo cerâmico (Scientia 2008), o que levou à exclusão das datações relacionadas ao lítico profundo pelo presente estudo. No entanto, se estudos posteriores indicarem que se trata apenas de uma movimentação de líticos se deslocando para camadas profundas, podemos ter um recuo ainda maior nas datações antigas para as ocupações cerâmicas do sítio (Tabela 1).

Ao observar as datas é possível perceber uma aparente incoerência estratigráfica, impressão decorrente do fato da unidade 150-5AV ser anômala ao padrão do sítio, uma vez que a mesma se encontra em uma área de baixa vertente, sujeita à deposição de colúvio (incluindo material arqueológico) proveniente da parte mais alta do sítio. Assim, enquanto as demais unidades, localizadas na média e alta vertente da colina em que se encontra o sítio, raramente chegavam a um metro de profundidade, a unidade 150 $5 \mathrm{AV}$ possuía uma camada arqueológica com espessura superior a 2 metros.

Outra questão é referente aos grandes intervalos entre as três datas mais recentes, justamente as que são relevantes para o presente estudo. Visto que todas as amostras estavam associadas ao pacote cerâmico, não há motivo para descartar nenhuma das datas, restando supor que o sítio foi reocupado depois de longos períodos, e que os intervalos não ficaram visíveis na estratigrafia. 


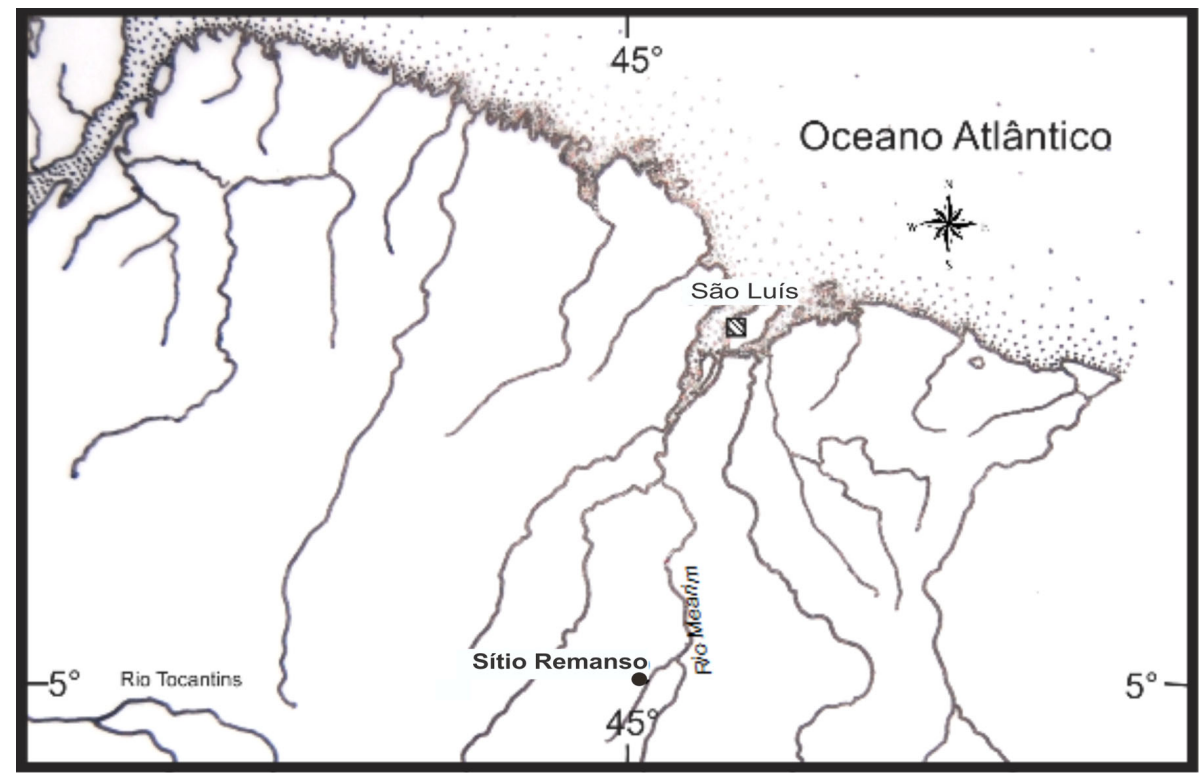

Figura 2 - Localização do sítio Remanso. Mapa: Fernando O. de Almeida

Tabela 1

Datações radiocarbônicas do sítio Remanso

\begin{tabular}{|c|c|c|c|c|c|}
\hline Amostra & Quadra & Nível & $\begin{array}{c}\text { Método de } \\
\text { Datação }\end{array}$ & Data & $\begin{array}{r}\text { Material } \\
\text { Associado }\end{array}$ \\
\hline Re-03 & $8 \mathrm{~A}$ & $60-70 \mathrm{~cm}$ & $\mathrm{C} 14^{1}$ & $2450 \pm 50$ a.C. & Lítico \\
\hline Re-02 & $250 \mathrm{~A}$ & $90-100 \mathrm{~cm}$ & C14 & $2390 \pm 190$ a.C & Lítico \\
\hline Re-05 & $150-5 \mathrm{AV}$ & $120-130 \mathrm{~cm}$ & C14 & $1600 \pm 100$ a.C. & $\begin{array}{l}\text { Lítico e } \\
\text { Cerâmico }\end{array}$ \\
\hline Re-04 & $150-5 \mathrm{AV}$ & $90-100 \mathrm{~cm}$ & C14 & $380 \pm 60$ a.C & $\begin{array}{l}\text { Lítico e } \\
\text { Cerâmico }\end{array}$ \\
\hline Re-01 & $250 \mathrm{~A}$ & $30-40 \mathrm{~cm}$ & C14 & AD $1320 \pm 80$ & $\begin{array}{l}\text { Lítico e } \\
\text { Cerâmico }\end{array}$ \\
\hline
\end{tabular}




\section{ANÁLISE DA CERÂMICA DO SÍTIO REMANSO}

A análise cerâmica do sítio Remanso contou com aproximadamente 700 fragmentos diagnósticos (i.e. bordas, bases, paredes decoradas e apêndices). Durante a análise foi observado que era impossível identificar uma técnica de manufatura acordelada, diferentemente do material dos demais sítios (Almeida 2008; Scientia 2008), o que indica o uso de uma técnica alternativa, provavelmente modelada. Heckenberger (2005: 210) indica que a cerâmica inciso-modelada (Barrancóide) do alto Xingu era feita desse modo (modelada), o que dá respaldo para essa possibilidade no sítio Remanso.

Conforme já apontado, as cerâmicas do sítio Remanso também contrastavam quanto ao uso de antiplástico. Enquanto os agrupamentos Tupi-Guarani e JêTimbira possuíam respectivamente cerâmica com antiplástico mineral e vegetal, o sítio Remanso possuía cerâmica predominantemente temperada com argila moído. Esta, que também é conhecida como "tabatinga" (Figueiredo 1965) ou "saibro" (Gomes 2005), talvez não seja o antiplástico mais adequado para problemas de performance (Schiffer \& Skibo 1997), como o do choque térmico. No entanto, a argila moída é extremamente adequada para a execução de algumas decorações plásticas (Rye 1981:4), tais como os motivos incisos que são comuns no sítio Remanso.

Outro aspecto que também chamou a atenção foi o da espessura dos vasos. Em geral, vasos grandes requerem paredes mais espessas para o suporte da estrutura. Para o armazenamento, paredes espessas tendem a reter o vapor que entra ou sai do vaso, como também tendem a ser mais resistentes na hora de amassar, mexer e misturar (Rice 1987:227). Os ceramistas do sítio Remanso parecem ter optado por alternativas que compensassem a fina espessura encontrada na maioria dos vasos. Rice (1987: 228) acredita que a necessidade por paredes grossas pode ser evitada pela manipulação da composição da pasta, como em um uso diferenciado do(s) antiplástico(s).

Mesmo no caso dos vasos grandes, feitos para suportar grandes volumes de água ou alimentos, notou-se que, sempre que possível, eram utilizados vasos com paredes finas (Figura 4). Sabe-se que para alguns grupos, como no caso das ceramistas Asurini, quanto mais fina a parede das vasilhas mais "bonita" esta é considerada, e, dessa forma à ceramista é atribuída uma maior habilidade (Silva 2000: 81).

Outro aspecto examinado foi o das formas cerâmicas. Foram separados 13 tipos de vasos, baseados nos distintos formatos (Figura 5).

Além dessas formas foram encontrados alguns fragmentos planos, prováveis assadores de alimentos (Figura 6). No entanto, diferentemente dos assadores corrugados encontrados na cerâmica Tupinambá do baixo Tocantins, os assadores do sítio Remanso possuíam como característica um alisamento grosseiro na face externa. Rice (1987: 129) indica que esse alisamento grosseiro seria adequado para melhorar a condução térmica do vaso, ainda que 


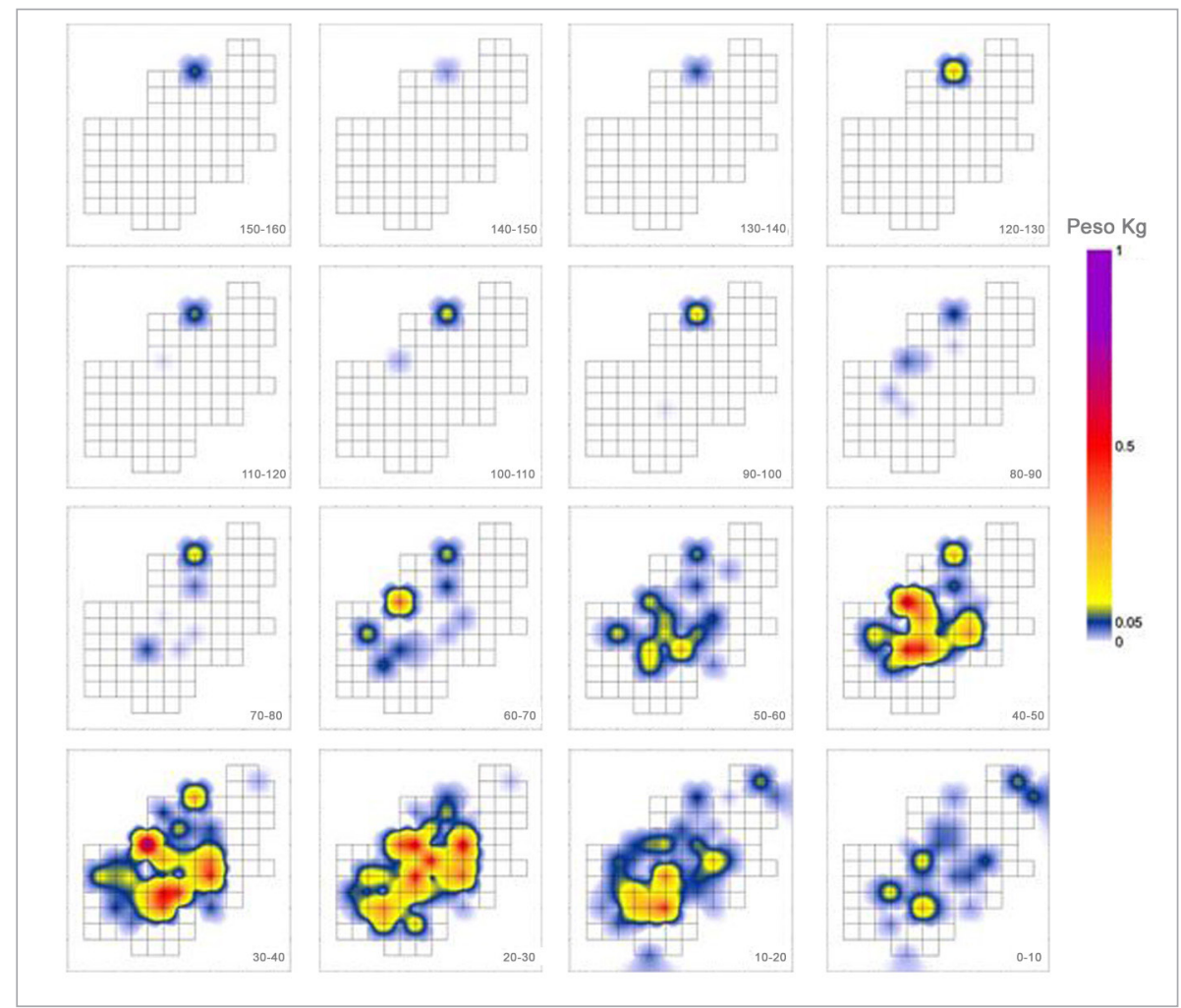

Figura 3 - Dispersão do material cerâmico, por peso, do sítio Remanso.

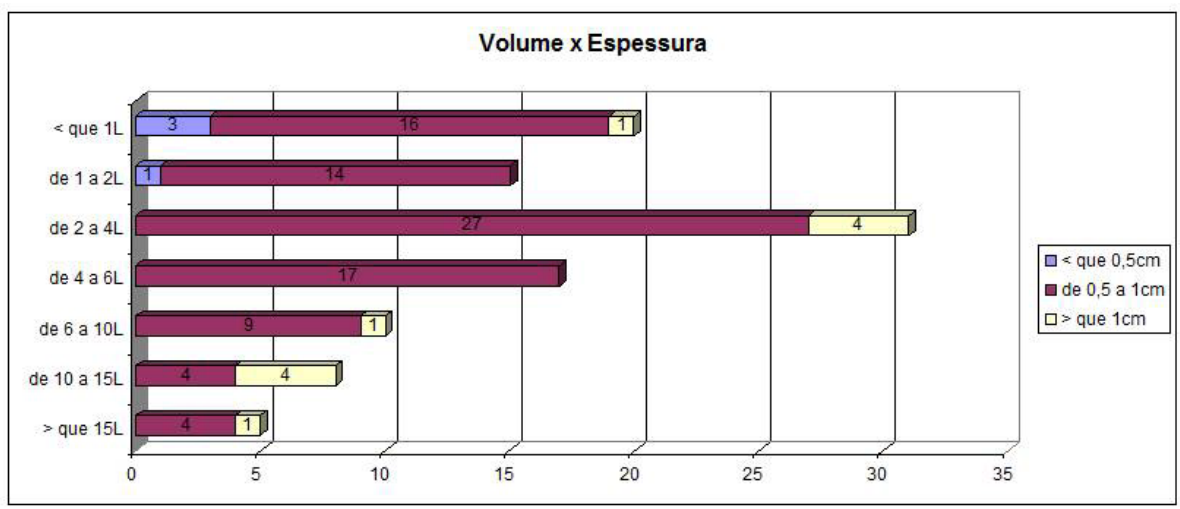

Figura 4 - Relação entre o volume e a espessura dos vasos cerâmicos reconstituídos do sítio Remanso. 


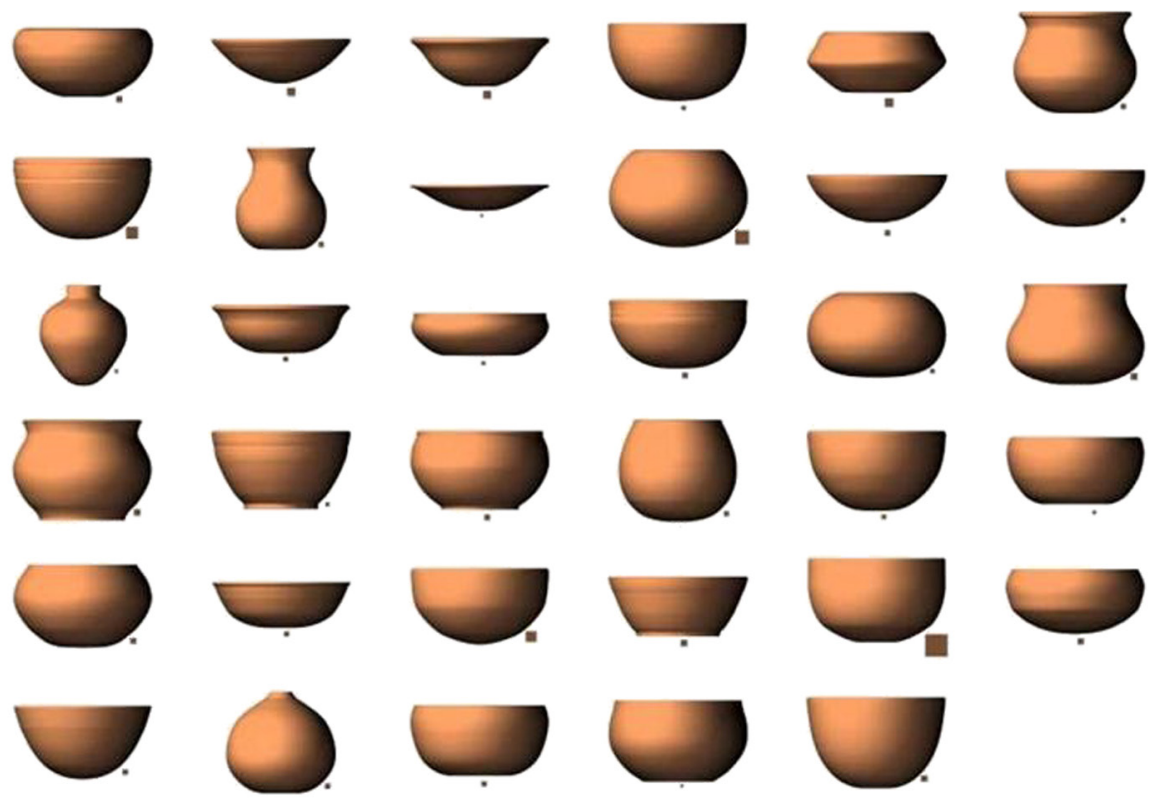

Figura 5 - Amostra aleatória de formas do sítio Remanso. O quadrado ao lado das peças mede $1 \mathrm{~cm}$.
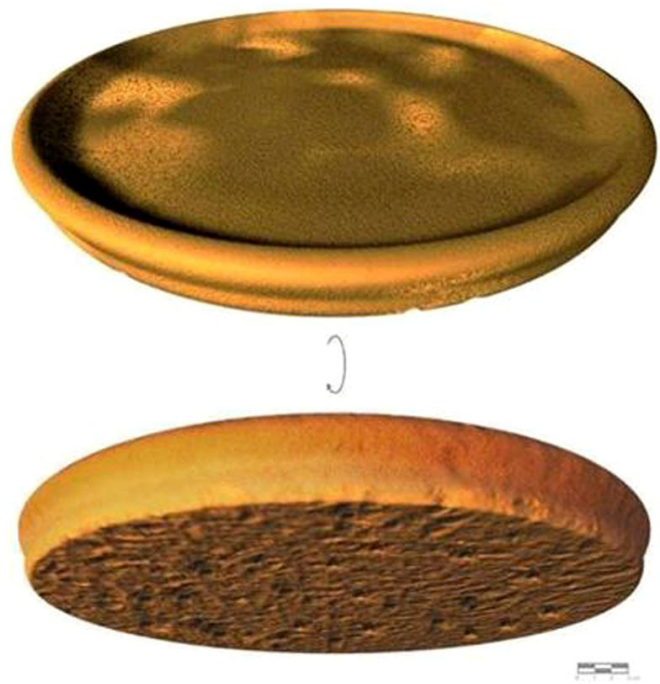

Figura 6 - Reconstituição de possível assador cerâmico do sítio Remanso, com a face externa mal alisada. 
este não seja um ponto definitivo nos debates sobre cerâmica. Por fim, como veremos, não há mudanças significativas nos padrões decorativos dos níveis inferiores para os superiores do sítio. Já no campo das formas, a principal mudança observada é que os assadores só aparecem nas camadas superiores. Se confirmada, essa mudança tecnológica pode significar uma alteração socioeconômica na estrutura do grupo que habitou o sítio Remanso.

\section{ASPECTOS DECORATIVOS}

A decoração da cerâmica do sítio Remanso é o que mais chama atenção de quem observa seus fragmentos, com um grande número de variáveis. A decoração pintada é encontrada de forma extremante simples, geralmente na forma de engobo, com a exceção de um único fragmento com motivo pintado sobre engobo, que será discutido com maior detalhe adiante.

Para realizar algum tipo de decoração a oleira tem, como primeiro passo, que escolher a área que vai ser trabalhada. Dentre as possíveis influências que pesarão na escolha dessa área, destacase o aspecto da visibilidade (Shepard 1995 [1956]: 261).

Pode-se observar que, do total de 97 fragmentos com decoração, 56 encontravam-se no bojo superior, na borda ou no lábio do vaso, ou seja, na parte superior do vaso, provavelmente o local mais visível (Figura 7). Há de se ressaltar que, mesmo quando encontrados na parede, os motivos não estavam necessariamente distantes da parte superior do vaso. No entanto, nada impede o contrário.

Para obter uma melhor compreensão quanto à decoração plástica, será realizada uma divisão entre: (1) desenhos com padrões bidimensionais, que nada mais são do que os motivos aplicados a superfícies variadas; e (2) figuras tridimensionais, que compõem os apêndices modelados, e que em geral são unitárias e representam seres zoomorfos. Como o primeiro é o mais recorrente, ele será também objeto de um maior aprofundamento que os demais.

\section{DESENHOS COM PADRÕES BIDIMENSIONAIS}

Uma breve observação (Figura 8) é suficiente para chegar à mesma conclusão alcançada por Shepard (1995[1956]: 259) quanto à dificuldade (durante a classificação da decoração cerâmica) de se traçar linhas seguras entre o naturalístico, o convencional e o geométrico, ou entre o simbólico e abstrato ou o puramente decorativo.

Os motivos desenhados na cerâmica do Remanso transpassam do regular para o irregular em um "jogo entre o igual e o diferente" que, segundo Müller (1990:244), está presente em diferentes sistemas cognitivos da cultura, como da cosmologia ritual e da mitologia.

No entanto, a interpretação desses motivos no presente contexto não pode ultrapassar um caráter especulativo. Ribeiro (1992:43) acredita que para um observador "estranho" a análise dos desenhos tem um caráter muito mais 
hermético, uma vez que vem desacompanhada do texto etnográfico ditado pelo próprio artista, o que leva a uma visão, por parte do observador ocidental, muito mais "sintética e abstrata". Quanto às figuras geométricas, Shepard (1995[1956]: 259) acrescenta que algumas vezes é até possível reconhecer a figura geometrizada, mas quando não

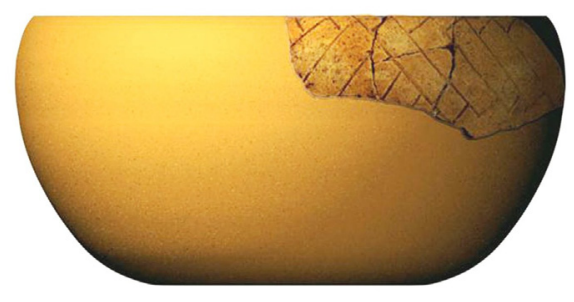

Figura 7 - Reconstituição do vaso a partir do fragmento 485 indicando decoração na parte superior do vaso (Fonte: Scientia 2008).

há a história desse design, não há nenhuma prova de seu significado.

Ainda assim, algumas sugestões podem ser feitas. Shepard (op.cit.: 259), acredita que o significado de um design deve ser buscado, sempre que possível. Muitos trabalhos realizados (Roe 1982; Helms 1993; Ribeiro 1992) indicam a possibilidade de observar a existência de elementos e estruturas comuns na arte indígena, através do cruzamento de materiais de diferentes grupos.

Reichel-Dolmatoff (1976) busca relacionar a utilização de alucinógenos por grupos indígenas com a criação dos motivos geométricos encontrados na cultura (cerâmica, cestaria, pintura corporal etc.) de diversos grupos amazônicos. $\mathrm{Na}$ opinião do autor, al- guns motivos são tão elementares que "podem surgir independentemente em qualquer época; são círculos, losangos, pontos, espirais e pouco mais" (op. cit.:90). Reichel-Dolmatoff considera que tais símbolos derivam dos chamados "fostemas", cujo significado ele empresta do trabalho de Oster (1970 apud Reichel-Dolmatoff 1976) que os define como "imagens subjetivas que aparecem no nosso campo de visão na obscuridade ou na penumbra, independentemente de uma luz externa e que, ao se originar no olho e no cérebro constituem um fenômeno próprio dos seres humanos". O trabalho de Oster, por sua vez, conta com uma listagem de fostemas, apresentadas a seguir (Figura 9).

Se os padrões decorativos bidimensionais podem ser fruto de um contínuo ato de retrabalhar os fostemas, por parte da mente humana, por outro lado, muitos podem ser encaixados na categoria "elementar descontínua" utilizada por Munn (1966:940). Tal categoria coloca cada item da composição dos padrões em classes com significados heterogêneos, onde apenas uma é significativa em cada momento. A autora usa o triângulo, também presente nos motivos do sítio Remanso, como exemplo dessa heterogeneidade, podendo hora significar, por exemplo, uma montanha, ou uma tenda, ou o corpo de uma pessoa. Adiante serão retomadas as propostas de Munn. Para tanto, será necessário transitar em outros campos relacionados aos padrões decorativos bidimensionais do sítio Remanso, o primeiro dos quais trata da simetria. 


\section{SIMETRIA}

Um dos pontos observados nos motivos é o da simetria. Shepard (1995[1956]: 263) define três tipos de simetria: bilateral, rotacional e radial. Como exemplos ela usa um triângulo isósceles e a figura humana para o primeiro, um paralelogramo e uma suástica para o segundo, e uma estrela do mar para o terceiro. Todos teriam em comum o fato de um ponto fundamental ser repetido sobre um eixo. Foi observado que um número signifi- cativo de motivos do sítio Remanso se encontra nas duas primeiras categorias (Figura 10).

Como no presente estudo foram analisados apenas fragmentos de vasos e não vasos inteiros, muitas vezes um motivo possivelmente simétrico passou uma impressão de assimetria. Nos exemplos simétricos levantados por Shepard (1995[1956]: 280) podemos observar que, dependendo da maneira que se faz um recorte (ou uma quebra) sobre um motivo, a simetria é total-

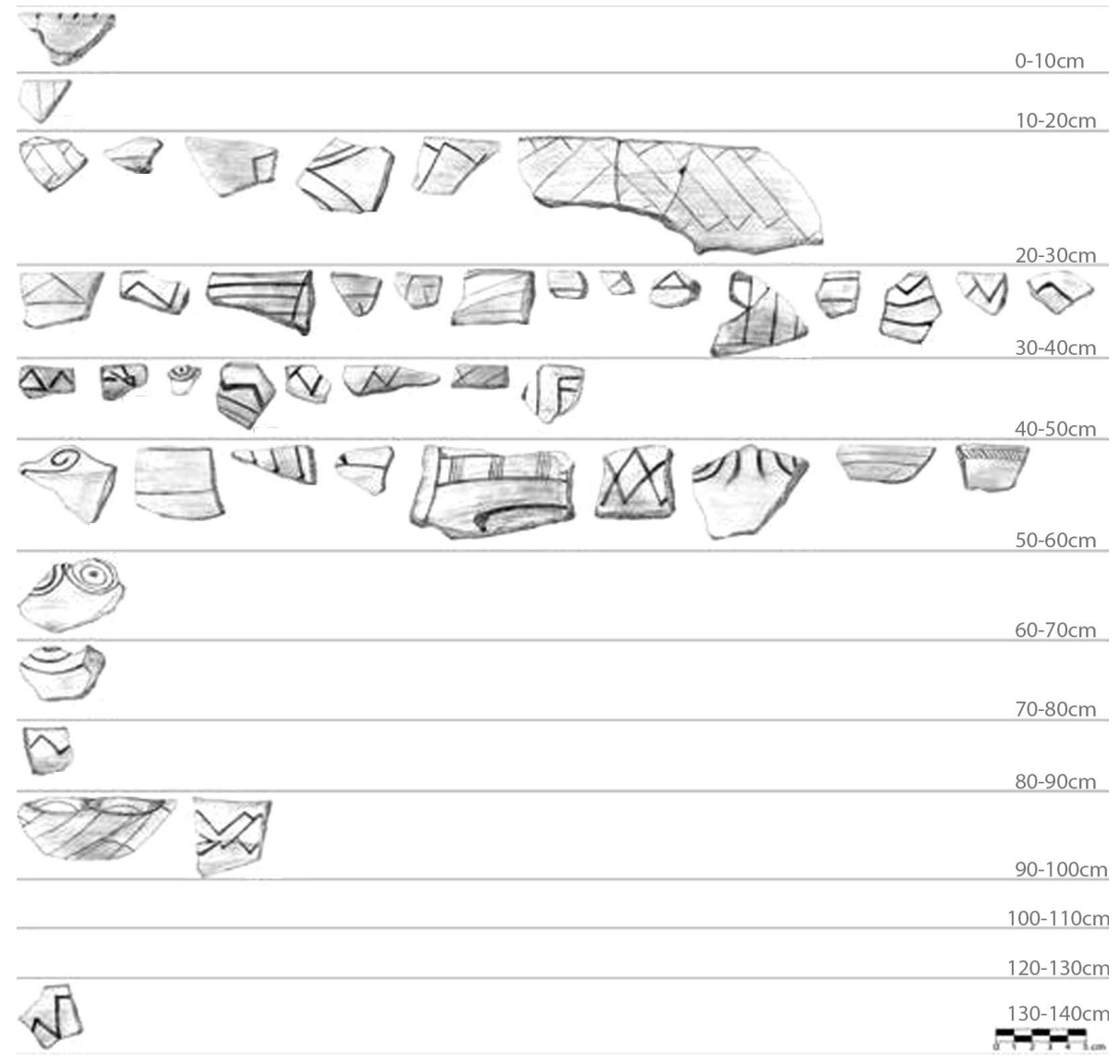

Figura 8 - Desenhos compostos por formas geométricas, encontrados por nível, e se repetindo de forma mais ou menos regular. 


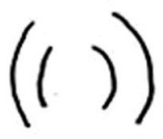

1

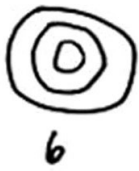

6

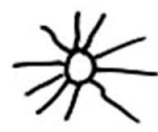

2

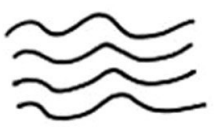

3

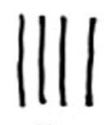

4

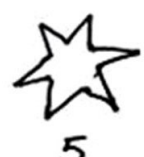

5

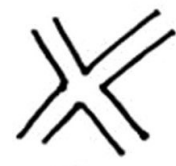

11
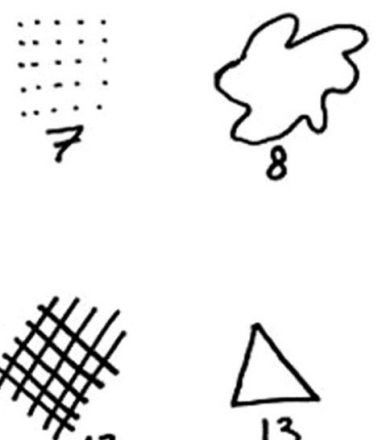

12.

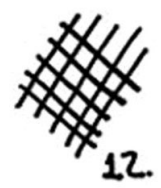

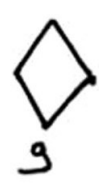

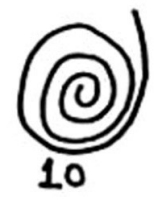

Figura 9 - Motivos baseados em fostemas (Reichel-Dolmatoff 1976:91).

mente obscurecida (Figura 11).

Tal processo certamente ocorreu com os motivos do sítio Remanso. Em alguns casos, o simples prolongamento das linhas pode clarear uma simetria obscurecida. Em outros é apenas possível sugerir a simetria como opção (Figuras 12 e 13).

O processo de domínio do simétrico em uma superfície curva, muitas vezes irregular, não é instantâneo. Para Lagrou (2007:104) o desafio não reside no caráter assimétrico ou na originalidade por trás de um campo simétrico, e sim na destreza de aplicar o padrão (sem deformá-lo) sobre uma superfície irregular e na coerência do desenho.

Dependendo do grau de complexidade, o domínio desta técnica pode levar anos a ser aprendido. A forma com que conhecimentos são passados, a transmissão cultural, é um processo cumulativo de interesse primordial para a arqueologia. No entanto, a dificuldade em lidar com curtos espaços temporais, como o de um período de aprendizagem, cria uma barreira quase intransponível para os arqueólogos, cuja alternativa etnoarqueológica é um dos poucos atenuantes para lidar com essas situações.

\section{PROCESSO DE APRENDIZAGEM}

"O estilo artístico não demonstra nenhuma tendência de quebrar com a tradição, pois a criatividade é considerada possível somente dentro e nunca fora de sua rede especí- 
fica de sentidos sociais e sensíveis." (Lagrou 2007: 100).

Em diversos contextos etnológicos foi observado que, quanto maior for o controle do instrutor sobre o aluno durante o processo de aprendizagem, maior será a semelhança estilística dos objetos por eles produzidos (Roe 1995). Dessa forma, nesse momento será utilizado o estudo piloto realizado por Crown (1999), que faz um detalhado estudo sobre a aprendizagem de motivos com base em seu trabalho etnoarqueológico no sudoeste dos Estados Unidos. A autora chega, entre outras inferências, às seguintes conclusões: (1) crianças têm a tendência de ser econômicas quanto ao uso de unidades de desenho, usando a repetição de motivos ao invés de diferentes atributos, assim como (2) do uso de formas vazias. $\mathrm{O}$ uso do hachurado só apareceria em um estágio posterior do desenvolvimento. (3) O conhecimento
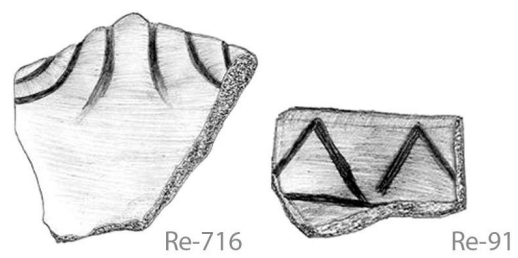

da "estrutura gramatical decorativa" subjacente a uma determinada cultura, aprendida através de uma repetição de regras, seria dominado por crianças entre idade de sete a nove anos. (4) O uso da simetria já apareceria em uma idade anterior, por volta de uns quatro anos, no entanto, não ficando totalmente dominado antes de uns sete anos de idade. (5) Outro aspecto seria o do respeito à forma do vaso, no qual designs que claramente respeitam o formato são mais avançados do que os que ignoram a forma das paredes do vaso. (6) A aprendizagem dos motivos começa com os mais simples (linhas, círculos, etc.), aumentando a complexidade por volta de uns sete anos. (7) A sobreposição dos motivos tende a ser evitada na etapa inicial de aprendizagem (quatro a sete anos), só aparecendo em uma fase posterior. Quanto à questão da coordenação motora, a autora conclui que (8) com o desenvolvimento do indivíduo este passa a fazer linhas

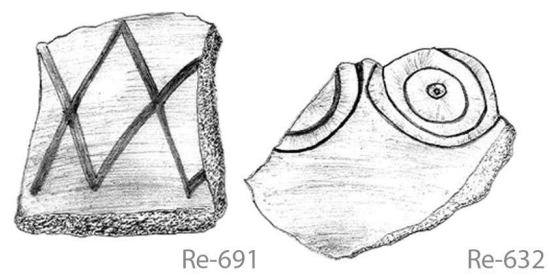

Figura 10 - Exemplos de simetria bilateral (Re-716 e Re-91) e exemplos de simetria rotacional (Re-691 e Re-632).
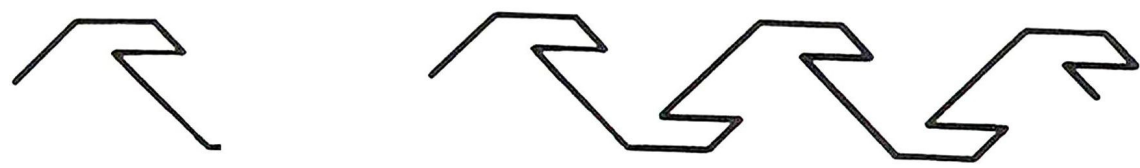

Figura 11 - Exemplo de como o recorte de um motivo - o que muitas vezes ocorre com a quebra do vaso cerâmico - pode mascarar uma simetria. (fonte: Shepard 1995[1956]: 280). 

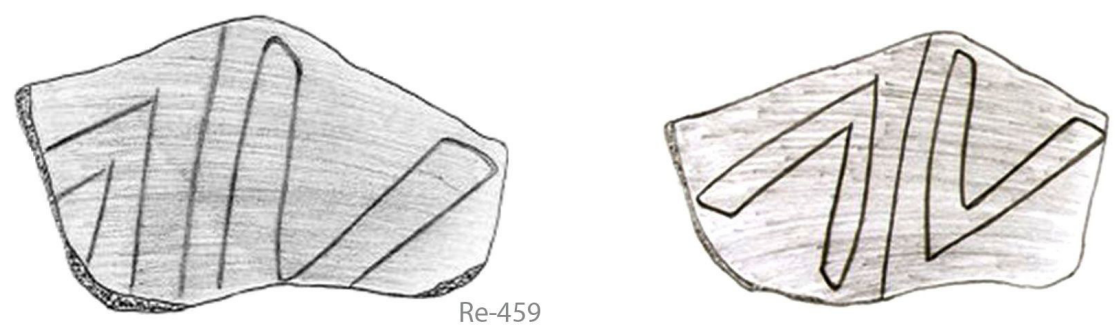

Figura 12 - Exemplos de simetria que podem ser detectados pelo prolongamento das linhas dos motivos. Pode-se observar ser um caso de simetria refletida e invertida de uma figura. Reconstituição aproximada.
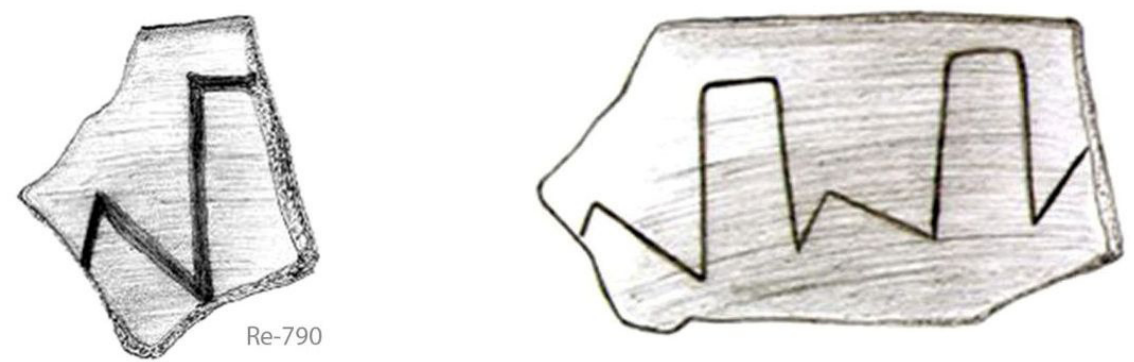

Figura 13 - Em outros casos o simples prolongamento das linhas não é suficiente para detectar algum mascaramento da simetria, ficando a última, nesse caso, apenas sugerida. Reconstituição aproximada.

que, individualmente e com relação a outras, sempre possuem mesma largura (9) e que por volta dos sete anos já seria possível ter um bom controle do traçado com relação à direção.

A partir desse estudo seria possível fazer algumas sugestões, apesar de correr o risco de confundir uma pequena criança com um artesão maduro, mas pouco habilidoso, para os motivos do sítio Remanso. Um exemplo seria o dos padrões retangulares que apareceram com alguma regularidade dentro do material estudado. Tal motivo pode ser encontrado nos fragmentos
Re-303, 312, 485, 513 e 705 (Figura 14). Pode-se partir do pressuposto de que tal motivo não deveria ser um dos primeiros na fase de aprendizagem dos(as) oleiros(as) uma vez que exige um conhecimento mínimo de forma, simetria e do contorno do vaso, já que tudo indica serem desenhos que se repetem por todo o perímetro do vasilhame.

Ainda assim, o fragmento 303 seria um bom exemplo de um artesão que não domina ainda as técnicas decorativas: linhas com espessura variável, direção oscilante e falta de simetria entre os 
retângulos que são encontrados de forma assimétrica sobre a superfície do fragmento. Seria, então, um exemplo de uma criança ainda com as faculdades motoras em desenvolvimento, provavelmente entre uns cinco e sete anos. $\mathrm{O}$ fragmento 312, por sua vez, já indica um avanço com relação ao anterior: linhas com espessura mais homogênea, retilíneas, com um maior respeito à forma do vaso, mas apresentando uma falta de regularidade na repetição das figuras. Ter-se-ia, então, um indivíduo com um maior desenvolvimento das faculdades motoras, provavelmente com uma idade próxima dos sete anos, ainda que não possuidor de um domínio completo do artesanato. $\mathrm{O}$ fragmento 485 estaria próximo do ideal, com raras irregularidades. Os fragmentos 513 e 705, por fim, seriam amostras de oleiros com total domínio da manufatura. Uma quase perfeita regularidade, respeitando o contorno do vaso, com linhas finas e retas. O domínio dos padrões regulares por parte de alguns artesãos do grupo que habitou o sítio Remanso encontra-se então "perfeitamente" representado.

\section{FIGURAS TRIDIMENSIONAIS}

As figuras tridimensionais presentes na cerâmica do sitio Remanso foram identificadas principalmente no uso dos apêndices zoomorfos, os "elementos contínuos” estabelecidos por Munn (1966:941). Tais elementos não possuiriam a heterogeneidade encontrada nos motivos geométricos. Segundo Munn, o esquema de uma árvore pode até ser usado para uma diferente variedade de árvores, mas não pode significar um poço ou fogo, e outros tipos de classes de fenômenos.
A inserção das figuras tridimensionais do sítio Remanso na categoria dos "elementos contínuos" é problemática. Além de não serem encontradas em número suficiente para uma análise mais sistemática, as figuras tridimensionais do sítio Remanso são bastante dúbias, por vezes contrariando o caráter homogêneo indicado por Munn (1966), como se verá a seguir.

Os apêndices zoomorfos, feitos de preferência através da técnica da modelagem, constituem a mais recorrente representação figurativa encontrada no sítio Remanso (Figura 15). A representação figurativa dos animais se dá de forma que suas características físicas não obedecem necessariamente ao modelo original, o que faz de sua identificação uma tarefa delicada (Schaan 1996:142).

Como afirmado anteriormente, a passagem do campo geométrico, bidimensional, para o campo figurativo, tridimensional, se faz por uma linha tênue. Algumas das figuras inseridas no campo dos desenhos geométricos poderiam ser transpostas, sem grande dificuldade, para o campo iconográfico, como nos exemplos abaixo (Figura 16).

Se forem subtraídos esses putativos zoomorfos, pouco resta para ser analisado quanto à iconografia. Dessa forma, para não empobrecer essa discussão, não só os possíveis animais estilizados serão incorporados, como será realizada uma discussão mais generalizada a respeito desse tipo de representação, mesmo no risco de adentrar um campo demasiadamente especulativo.

Para a análise iconográfica do sítio Remanso será utilizado como base o 

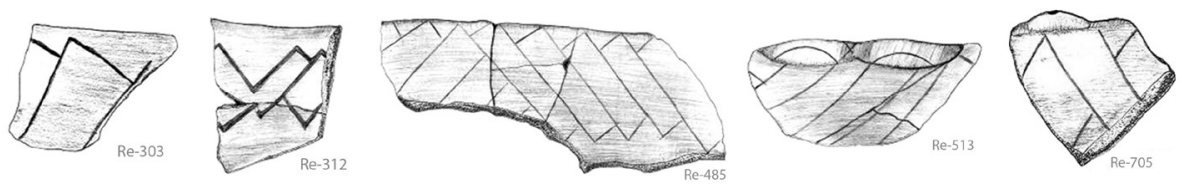

Figura 14 - Padrões bidimensionais com decoração retangular (desenhos fora de escala).

modelo esquemático elaborado por Roe (1982:128) para a cosmologia dos Shipibo, grupo de língua Pano da Amazônia peruana. Para o autor (op. cit.:18), a cosmologia seria o total de ideias sobre a natureza e a composição do mundo ou do universo que está contido em qualquer sistema cultural. Roe (1982) acredita que seu trabalho teria de ser compreendido como uma metacosmologia, um sistema não encontrado em todos seus detalhes em qualquer grupo tribal, mas um que pode estar por trás de boa parte das cosmologias tribais amazônicas.

Pode-se observar no esquema de Roe (1982:261) a relação dos animais aquáticos, como o sapo (presente na iconografia do sítio Remanso: Re-156), com um submundo escuro, negativo. Nessa categoria estariam inseridos também os peixes e o jacaré que, da mesma forma, estariam ligados a um universo feminino.

Por outro lado, as aves (talvez representadas no sítio Remanso: Re-538, Re-471), com a possibilidade de voar para um "mundo superior", estariam extremamente ligadas com um universo masculino. Pode-se dar como exemplo o urubu e o gavião (Roe 1982:261). Gomes (2005:226) acredita que animais como o urubu rei e o morcego possuem significado simbólico ligado ao xamanismo. Schaan (1996: 143) associa a coruja, talvez representada no fragmento
Re-471, e certamente representada na cerâmica inciso-modelada do interflúvio Tocantins-Xingu (Garcia 2012), a rituais funerários, uma vez que ela é frequentemente vista comendo pequenos animais inteiros e expelindo apenas seus ossos, em forma de pelotas. Roe (1982:261) liga a vida noturna da coruja, como uma vigilante dos mortos, ao universo feminino.

Resumindo, se esses registros provêm de diversos exemplos distintos, no tempo e espaço amazônico, está claro que o material do sítio Remanso dialoga com eles, o que contribui para a ideia de uma linguagem pan-amazônica encontrada em alguns estilos cerâmicos Inciso-modelados. Estilos formados pela combinação de componentes bidimensionais e tridimensionais que indicam que "a simbologia presente nos objetos arqueológicos e etnográficos pode ser relacionada a um corpo de mitos e narrativas indígenas e que seu papel enquanto agente de reprodução e transformação da cultura pode ser estudado no passado e no presente" (Barreto 2008: 21).

\section{DECORAÇÃO PINTADA: O MOTIVO ÚNICO}

Foi identificado apenas um motivo pintado na cerâmica do sítio Remanso, recorrentemente encontrado na cerâmica Tupinambá do baixo Tocantins (Figura 17). Voltarei a esse ponto. 
DISCUSSÃO DOS DADOS: A POSSIBILIDADE BARRANCÓIDE

Por volta de 3000 a.C., na boca do rio Amazonas e no litoral do que é hoje o estado do Pará, aparece um complexo cerâmico denominado Mina. Essa cerâmica estaria associada a sambaquis de coletores-pescadores. Segundo Simões (1981:78-79), a fase Mina seria constituída por vasos utilitários, com antiplástico de concha moída, por vezes com banho vermelho e decoração raspada e com "incisões incipientes".
Aparentemente, os produtores da cerâmica Mina não se restringiram apenas ao litoral paraense. Por exemplo, na ilha do Maranhão, onde se encontra hoje a cidade de São Luís, Bandeira (2008; 2010) também encontrou cerâmica da fase Mina associada ao sambaqui do Bacanga. O curioso é que as datas do Sambaqui Bacanga não só corroboram as datas obtidas por Simões para fase Mina, como expandem a fase espacialmente e cronologicamente (transformando-a em uma Tradição), uma vez
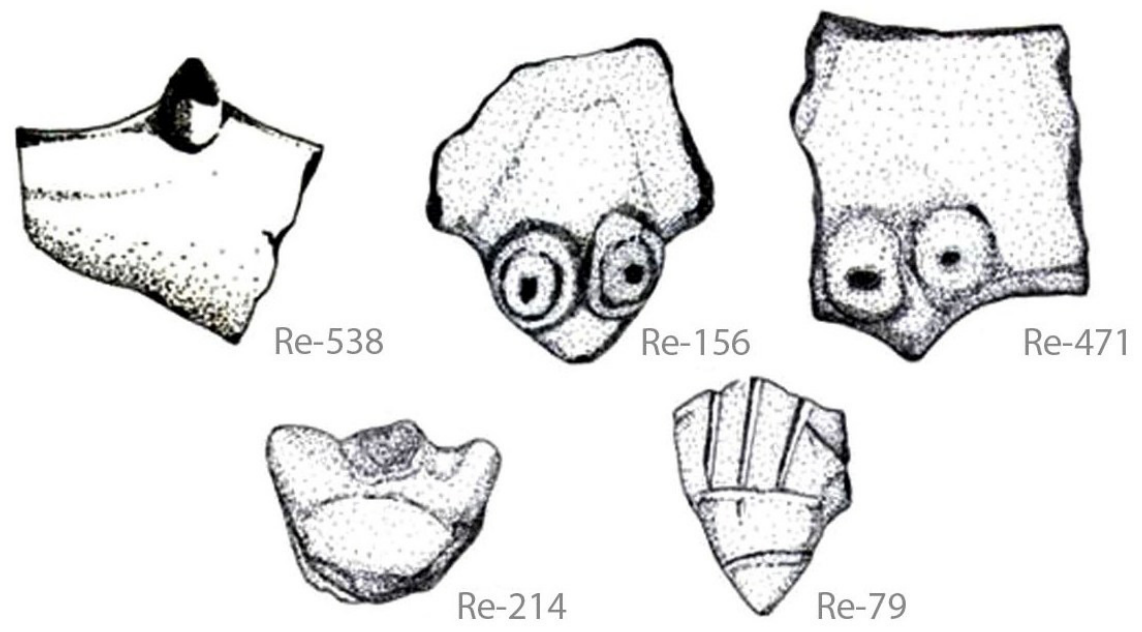

Figura 15 - Principais representações iconográficas presentes no sítio Remanso.
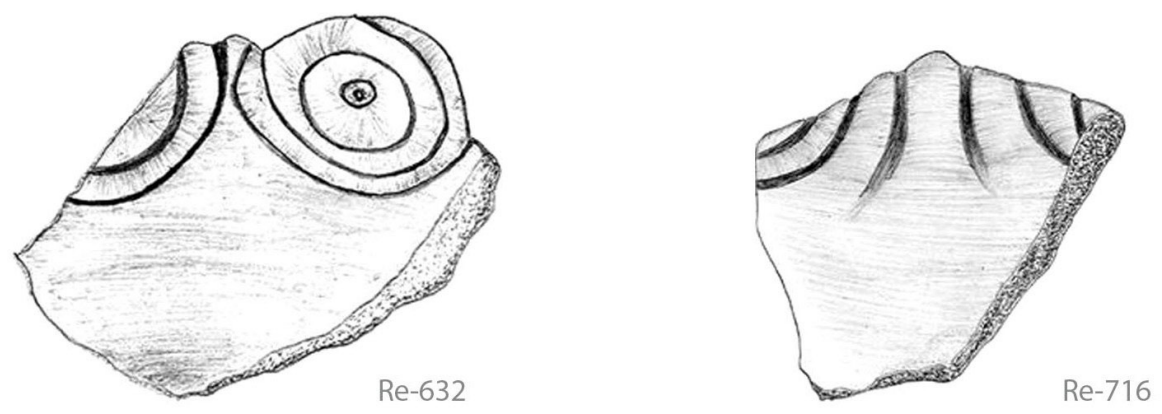

Figura 16 - Decorações que oscilam entre um padrão geométrico, bidimensional, e um figurativo, tridimensional. 
que a cerâmica Mina é datada nesse sítio, por termoluminescência, em 3.850 a.C.. Além disso, e o que chama ainda mais a atenção, é o fato da Tradição Mina não ser a ocupação cerâmica mais antiga desse sítio. Bandeira (2008:152) encontrou sob a espessa ocupação Mina uma cerâmica desvinculada à "construção" do sambaqui, com uma data, por TL, de 4.650 a.C.

Essa ocupação pode estar relacionada à fase Uruá. Silveira e Schaan (2005: 68) indicam que é essa fase, identificada no litoral do Pará, que está relacionada com a controversa data não publicada por Simões, de 3.620 125 a.C. (Roosevelt 1995: 117). No entanto, não está clara a diferença entre a cerâmica da fase Uruá e da Tradição Mina, e se realmente há alguma relação entre essa fase e a ocupação pré-sambaqui identificada por Bandeira. $O$ fato da fase Uruá ser relacionada a grupos sambaquieiros (Silveira e Schaan 2005) sinaliza que não.

Bandeira acaba por não realizar uma análise comparativa entre a cerâmica das duas ocupações do sambaqui do Bacanga, se limitando a dizer que a cerâmica pré-Mina possui antiplástico mineral, frente à cerâmica Mina que possui antiplástico de concha triturada (2008:293). No entanto, de posse das descrições realizadas por Simões para a cerâmica Mina, é possível sugerir, ainda que de maneira grosseira, que grande parte dos elaborados atributos funcionais e decorativos descritos por Bandeira (como alças, apêndices, incisões, excisões, escovados) fazem parte da ocupação pré-Mina. Segundo
Leite-Filho (2010: 764), o pesquisador Raimundo Lopes teria encontrado sítios (não datados) com características semelhantes em áreas lacustres maranhenses no início do século XX.

Dessa forma, ao que tudo indica, o sítio Remanso não seria o único sítio com cerâmica elaborada na região do atual estado do Maranhão com datas superiores a 1.500 a.C.. Além do mais, se há alguma relação entre a cerâmica do sítio Remanso com a cerâmica antiga do sítio Bacanga, então as datações por hora descartadas por serem consideradas pré-cerâmicas (i.e. 2.500 a.C.) passam a não ser tão absurdas assim.

Caso realmente haja uma relação entre as cerâmicas pré-Mina dos sítios Bacanga e Remanso, e caso a cronologia desses sítios seja confirmada, se delineia um panorama de grupos litorâneos entrando para o interior. Mas quem seriam esses grupos?

Lathrap (1970) indica uma grande onda migratória marítima de populações produtoras de cerâmica Barrancóide no norte da América do Sul, em um sentido oeste/leste. Se há realmente alguma relação entre esses grupos do norte com os grupos maranhenses, estes acabariam por inserir um toque de incerteza quanto ao ponto de partida, ao sentido dos movimentos, e à temporalidade em que estes movimentos ocorreram. A datação para cerâmica incisa e modelada obtida por Garcia (2012: 228) para a região de inerflúvio Xingu-Tocantins, que ultrapassa 1.000 a.C., é ainda outro elemento para complicar essa discussão. 
A cerâmica Barrancóide foi definida a partir dos estudos realizados por Osgood e Howard (1943) e Cruxent e Rouse (1958; Rouse \& Cruxent 1963) com base nas escavações dos sítios Barrancas e Saladero, no baixo rio Orinoco, na Venezuela. Posteriormente, cerâmicas arqueológicas com atributos e profundidade cronológica semelhantes foram encontradas em outras áreas da Amazônia, como no alto Amazonas (Lathrap 1962), no médio Amazonas (Hilbert 1968), na Guiana Inglesa (Evans \& Meggers 1960), e na Amazônia boliviana (Nordenskiöld 1924), levando esse material a ser considerado como uma Tradição ${ }^{2}$ por Lathrap (1970).

A cerâmica Barrancóide, no rio Orinoco, seria a sucessora da cerâmica Saladóide. Lathrap (1970: 113) indica que a primeira diferença entre os grupos produtores de cerâmica Saladóide e Barrancóide é a do padrão de assentamento. Enquanto nos sítios Saladóide o refugo material estaria concentrado em montículos de tamanho limitado, os sítios Barrancóides possuiriam refugo espalhado de forma homogênea e extensa, acompanhando o leito do rio. Por outro lado, autores como Heckenberger (2005), Moraes (2007, 2010) e Neves (2008) correlacionam as ocupações Barrancóides com aldeias circulares.

A diferença entre as cerâmicas Saladóide e Barrancóide é que a primeira seria caracterizada pela combinação de decoração incisa com pintura vermelha sobre branco, enquanto que a cerâmica Barrancóide possuiria como principais atributos diagnósticos a decoração incisa geométrica, feita em bordas largas (reforçadas), apêndices modelados zoomorfos, e apenas raramente banhos com pigmentos vermelhos e brancos (Gomes 2005: 291; Lima 2008: 32). Segundo Lathrap (1970: 114), os motivos incisos seriam relativamente simples, quando não possuíam a ambição de ser representativos. Assadores de mandioca também estariam presentes na indústria cerâmica dessa Tradição.

Para Lathrap (1970:123), que vincula essa cerâmica com os falantes da família Aruaque, a Tradição Barrancóide começaria a se espalhar a partir da Amazônia Central durante o primeiro milênio A.C. No entanto, uma cerâmica do estilo Barrancóide foi datada em
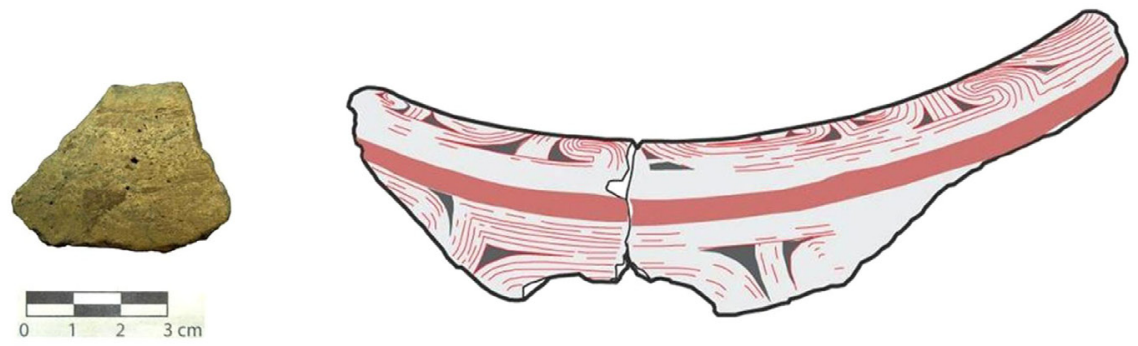

Figura 17 - Fragmento 85, com motivo pintado (sítio Remanso), e reconstituição de fragmento policrômico, com repetições do mesmo motivo, pertencente ao sítio Santa Cruz (Subtradição Tupinambá da Amazônia). (Foto: Fernando Ozorio de Almeida; Desenho: Daniel Roldão). 
mais de 1.500 anos A.C. por Roosevelt (1999) na Caverna da Pedra Pintada, no baixo Amazonas, indicando que a cronologia Barrancóide é mais recuada, e que muitas das pistas para compreender esses grupos se encontram no oriente amazônico.

Tendo essas características em mente, admite-se que denominar o sítio Remanso como sendo um sítio Barrancóide é um pouco prematuro, visto que a região em que o sítio se encontra não é conhecida por possuir essa cerâmica, nem por possuir falantes de línguas Aruaque. No entanto, sabe-se que a vinculação dessa Tradição com os falantes dessa família linguística é problemática. Por exemplo, estudos em regiões como a Amazônia Central apontam para contextos Barrancóides multiétnicos (Lima 2008; Neves 2008), o que não desqualifica a proposta de Lathrap, mas propõe um cuidadoso olhar contextual para cada uma das regiões estudadas. Portando, no presente artigo, optou-se por denominar o material apenas de inciso-modelado de maneira heurística, significando, apenas, uma antiga cerâmica Amazônica com acabamento elaborado (com as características diagnósticas citadas). Acredita-se que tal abordagem possa a facilitar a compreensão dos antigos grupos ceramistas que estão sendo revelados por diversos estudos no leste Amazônico e imediações (Bandeira 2008, 2010; Garcia 2012). Assim, a possibilidade de correlação desse material inciso-modelado com a Tradição Barrancóide se restringe a apenas um dos possíveis e atrativos planos de tra- balho para futuros estudos na periferia da Amazônia Oriental.

O estudo dos vestígios arqueológicos do sítio Remanso, que parecem indicar uma sequência de ocupações de um mesmo local por um mesmo grupo por um longo espaço de tempo, com regras rígidas de se fazer cerâmica, parece se encaixar no quadro tecido por Roosevelt (1999: 267) para as sociedades antigas pouco complexas da Amazônia. A autora acredita que tais sociedades, exatamente por não possuírem um alto grau de complexidade sociopolítico, teriam, por vezes, suportado melhor as contingências históricas do que sociedades mais centralizadas e estratificadas. A repetição dos padrões decorativos, aparentemente seguindo um rigoroso período de aprendizado, e a persistência temporal de uma cerâmica que sempre possui o mesmo antiplástico, cor e espessura padronizadas, parecem corroborar a ideia de um grupo que conseguiu manter por muito tempo uma forma peculiar de fazer cerâmica.

Por outro lado, as datas pré-coloniais para a parte superior da estratigrafia do sítio indicam que este já não era mais habitado pelo grupo que produzia cerâmica inciso-modelada no início do período colonial. Ainda é cedo para chegar a uma conclusão do motivo do fim da ocupação do sítio pelos produtores dessa tradição cerâmica. No entanto, o adensamento das datas vinculadas com grupos produtores da cerâmica da Subradição Tupinambá Amazônica no entorno do baixo rio Tocantins, por volta do ano 1.000 
d.C. (Almeida 2008; Almeida e Garcia 2008), assim como o surgimento de um novo complexo cerâmico (Scientia 2008), talvez vinculado a um contexto Jê-Timbira, pode ser a explicação para o fim das ocupações. A presença de um fragmento com um motivo tipicamente Tupinambá Amazônico no topo do pacote arqueológico do sítio Remanso, parece indicar o contato entre os habitantes desse sítio Remanso com os Tupinambá. Assim, visto o caráter belicoso dos grupos falantes de línguas Tupi-Guarani na Amazônia (Fausto 2001; Viveiros de Castro 1986) e dos grupos Jê-Timbira do interior do Maranhão (Nimuendajú 1946, 1967), não seria de estranhar que esses grupos estejam relacionados com o fim da ocupação indígena no sítio Remanso.

No campo estilístico, Barreto (2008: 24) observa uma gradual mudança no padrão amazônico pré-histórico com o aparecimento de representações menos naturalistas, e mais estilizadas e geometrizantes, que possuiriam leituras mais restritas, representações que substituíram os estilos que possibilitavam uma leitura mais universal - e mesmo literal - de seus significados simbólicos. Se, na análise do material do sítio Remanso, isso fica sugerido pelo aparecimento de um único fragmento estilisticamente destoante, no topo da estratigrafia, e pela escassez geral de material nos níveis superiores $(0-15 \mathrm{~cm})$, no campo histórico essa ruptura parece mais clara, já que há aparentemente um predomínio quase completo de grupos Tupi-Guarani e Jê-Timbira no interior maranhense na época colonial.

\section{CONCLUSÃO}

A proposta desse artigo foi oferecer uma detalhada análise da cerâmica do sítio Remanso. Através dela foi discutida a presença de antigos grupos portadores de uma cerâmica com um elaborado sistema decorativo no leste da América do Sul. Aparentemente, estes grupos produziram uma cerâmica com pouca variabilidade temporal, o que deve estar relacionado a um rígido sistema de aprendizagem para sua confecção. Foi realizada uma tentativa de classificar e, com a devida cautela, interpretar parte dos motivos decorativos e figuras presentes nos vasos do sítio Remanso. Foi notado que esse sítio possui um estilo particular, se comparado aos demais sítios da região, principalmente quanto aos padrões decorativos bidimensionais e as figuras tridimensionais. $\mathrm{O}$ uso combinado dessas ferramentas estilísticas e o efeito comunicativo decorrente podem futuramente ligar o sítio Remanso a esse antigo complexo decorativo, assim como à Tradição Barrancóide, presente em uma série de lugares distintos na Amazônia pré-colonial.

Por fim, foi realizada uma breve discussão entre os dados desse sítio e os do sambaqui do Bacanga, encontrado no litoral Maranhense. As datas mais recuadas desse sambaqui, com relação ao sítio Remanso, assim como o aparecimento dos grupos portadores de cerâmica da Tradição Mina, poderiam indicar que os grupos com cerâmica inciso-modelada se movimentaram do litoral para o interior, talvez entre 4.000 e 3.000 a.C. Da mesma forma, 
o aparecimento de outros grupos précoloniais no interior do Maranhão no final do primeiro milênio d.C., com indústrias cerâmicas distintas, estaria ligado ao fim da ocupação do sítio Remanso. Hipóteses que, claro, terão de ser testadas no futuro.

\section{AGRADECIMENTOS}

A análise do sítio Remanso fez parte dos trabalhos arqueológicos referentes à implantação da Linha de Transmissão Tucuruí (PA)-Presidente Dutra (MA), realizados pela Scientia Consultoria Científica, sob coordenação da Dra. Solange Caldarelli. Agradeço a Maria do Carmo Santos, que coordenou nossos estudos cerâmicos, e os companheiros Rafael Pedott, Daniella Amaral, Lorena Garcia, Claide Moraes e Wesley Oliveira. Os desenhos dos fragmentos cerâmicos foram realizados pelo autor, Claide Moraes e Rafael Pedott. É impossível lembrar, depois de tanto tempo, quem fez qual. Sérgio da Silveira fez as reconstituições digitais e Daniella Novo fez a sua habitual revisão de texto. Agradeço a Eduardo Neves pela orientação e, especialmente, a Cristiana Barreto pelos comentários e sugestões com relação ao texto. Foi Agda Sardinha quem me estimulou a tirar esse material da gaveta.

\section{NOTAS}

${ }^{1}$ Beta Analytic.

${ }^{2}$ Rouse e Cruxent (1963: 23) definem a cerâmica Barrancóide como uma Série, significando a recorrência de elementos em um amplo espaço temporal e geográfico, de maneira análoga à maneira com que Lathrap (1970) utiliza o termo Tradição.

\section{REFERÊNCIAS}

Abbeville, C. d'. 1975 [1614]. História da Missão dos Padres Capuchinhos na Ilha do Maranhão e Terras Circunvizinhas. Belo Horizonte/São Paulo: Itatiaia/Edusp.

Almeida, F. O. 2008. O Complexo Tupi da Amazônica Oriental. Dissertação de Mestrado. Museu de Arqueologia e Etnologia, Universidade de São Paulo, São Paulo, Brasil.

Almeida, F. O. de e L. G. Garcia. 2008. Aspectos do espaço Tupinambá. Revista de Arqueologia 21(2): 97-119.

Balee, W. 1994. Footprints of the Forest. Ka'apor Ethnobotany - the historical ecology of plant domestication by an Amazonian people. New York: Columbia University Press.

Bandeira, A. M. 2008. Ocupações humanas pré-históricas no litoral Maranhense: Um estudo de caso sobre o sambaqui Bacanga na ilha de São Luís, Maranhão. Dissertação de Mestrado. Museu de Arqueologia e Etnologia, Universidade de São Paulo, São Paulo, Brasil.

2010. Ocupações pré-históricas de pescadores-coletores-caçadores e ceramistas no litoral equatorial Amazônico: A antiguidade da cerâmica em foco, in Arqueologia Amazônica 2. Editado por E. Pereira e V. Guapindaia, pp. 655-680. Belém: MPEG/ IPHAN/SECULT.

Barreto, C. 2008. Meios místicos de reprodução social. Tese de Doutorado. Museu de Arqueologia e Etnologia, Universidade de São Paulo, São Paulo, Brasil.

Coelho, E. M. B. 1990. A Política Indigenista no Maranhão Provincial. São Luís: Sioge.

Crown, P. 1999. Socialization in American Southwest pottery decoration, in Pottery and People. Editado por J. M. Skibo, e G. M. Feinman, pp. 25-43. Salt Lake City: University of Utah Press. 
Cruxent, J. M. \& I. Rouse. 1958. An Archaeological Chronology of Venezuela. Washington D.C.: Pan America Union.

Evans, C. \& B. Meggers. 1960. Archaeological Investigations in British Guiana. Washington: Government Printing Office.

Évreux, Y. d'. 2002 [1614]. Viagem ao Norte do Brasil. Rio de Janeiro: Leite Ribeiro.

Fausto, C. 2001. Inimigos Fiêis: História, guerra e xamanismo na Amazônia. São Paulo: Edusp.

Figueiredo, N. 1965. A cerâmica arqueológica do rio Itacaiúnas. Boletim do Museu Paraense Emilio Goeldi, Antropologia 27:1-17.

Garcia, L. G. 2012. Arqueologia na região dos interflúvios Xingu-Tocantins: a ocupação Tupi no rio Cateté. Dissertação de Mestrado. Museu de Arqueologia e Etnologia, Universidade de São Paulo, São Paulo, Brasil.

Gomes, D. M. C. 2005. Análise dos padrões de organização comunitária no Baixo Tapajós o desenvolvimento do formativo na área de Santarém, PA. Tese de Doutorado. Museu de Arqueologia e Etnologia, Universidade de São Paulo, São Paulo, Brasil.

Heckenberger, M. J. 2005. The ecology of power: Culture, place, and personhood in the Southern Amazon, A.D. 1000-2000. New York: Routledge.

Helms, M. 1993. La cosmovisión de los Cacicazgos del istmo de Panamá, in La Antigua America: El arte de los paisajes sagrados. Editado por R. F. Townshed, pp. 217-228, Chicago: The Art Institute of Chicago.

Hilbert, P. P. 1968. Archäeologische Funde im oberen Amazonas-gebiet. Baesslerarchiv, 3: 205-255.

Huxley, F. 1956. Affable Savages. London: Heart Davis.

Lagrou, E. 2007. A fluidez da forma: Arte, alteridade e agência em uma sociedade amazônica (Kaxinawa, Acre). Rio de Janeiro: Topbooks.
Lathrap, D. W. 1962. Yarinacocha: Stratigraphic excavations in the Peruvian Montaña. M.S. Doctoral Dissertation. Harvard University, Cambridge, Estados Unidos. 1970. The Upper Amazon. New York: Thames \& Hudson.

Leite-Filho, D. C. 2010. Ocupações précoloniais no litoral e nas bacias lacustres do Maranhão, in Arqueologia Amazônica 2. Editado por E. Pereira e V. Guapindaia, pp. 771-773. Belém: MPEG/IPHAN/SECULT.

Lima, H. P. 2008. História das Caretas: a Tradição Borda-Incisa na Amazônia Central. Tese de Doutorado. Museu de Arqueologia e Etnologia, Universidade de São Paulo, São Paulo, Brasil.

Moraes, C. P. 2007. Arqueologia na Amazônia Central Vista de uma Perspectiva da Região do Lago do Limão. Dissertação de Mestrado. Museu de Arqueologia e Etnologia, Universidade de São Paulo, São Paulo, Brasil.

2010. Aldeias circulares na Amazônia Central: um contraste entre a fase Paredão e a fase Guarita, in Arqueologia Amazônica 2. Editado por E. Pereira e V. Guapindaia, pp. 581-604. Belém: MPEG/IPHAN/SECULT.

Müller, R. P. 1990. Os Asurini do Xingu: História e arte. Campinas: Unicamp.

Munn, N. 1966. Visual categories: An approach to the study of representational systems. American Anthropologist 68 (4): 936-950.

Neves, E. G. 2008. Ecology, ceramic chronology and distribution, long-term history, and political change in Amazonian Floodplain, in Handbook of South American Archaeology. Editado por H. Silvernan, e W. H. Isbell, W. H, pp. 359-378. New York: Springer.

Nimuendajú, C. 1946. The Eastern Timbira. Berkley-Los Angeles: University of California Press. 
1967. The Apinayé. Anthropological Publications, Oosterhout.

Nordenskiöld, E. 1924. Finds of graves and old dwelling-places on the Rio Beni, Bolivia. Ymer 44: 229-237.

Osgood, C. \& G. D. Howard. 1943. An archaeological survey of Venezuela. New Haven: Yale University Publications in Anthropology.

Reichel-Dolmatoff, G. 1976. O contexto cultural de um alucinógeno aborígene: Banisteriopsis Caapi, in Os Alucinógenos e o Mundo Simbólico. Editado por V. P. Coelho, pp. 59-103. São Paulo: EPU/ EDUSP.

Ribeiro, B. 1992. A mitologia pictória dos Desâna, in Grafismo Indigena. Editado por L. Vidal, pp. 35-52. São Paulo: Studio Nobel/ Edusp/ FAPESP.

2006. Diários Índios: os Urubus-Ka'apor. São Paulo: Companhia das Letras.

Rice, P. M. 1987. Pottery Analysis, a Sourcebook. Chicago \& London: University of Chicago Press.

Roe, P. G. 1982. The cosmic sygote: Cosmology in the Amazon Basin. New Brunswick: Rutgers University Press.

1995. Style, society, myth and structure, in Style, society and person. Archaeological and ethnological perspectives. Editado por C. Carr e J. E. Neeitzel, pp. 27-76. New York: Plenum.

Roosevelt, A. C. 1995. Early pottery in the Amazon: twenty years of scholarly obscurity, in The Emergence of Pottery. Editado por W. K. Barnett e J. W. Hoopes, pp. 115-131. Washington/London: Smithsonian Institution Press.

1999. The maritime-highland-forest dynamic and the origins of complex society, in History of the native peoples of the Americas: South America. Editado por F. Salomon e S. Schwartz, pp. 264-349. New York: Cambridge University Press.

Rouse, I. \& J. M. Cruxent. 1963. Venezuelan Archaeology. New Haven: Yale University Press.
Rye, O. S. 1981. Pottery technology: Principles and reconstruction. Washighton D.C.: Taraxacum.

Schaan, D. P. 1996. A linguagem iconográfica da cerâmica Marajoara. Dissertação de Mestrado. Pontifícia Universidade Católica do Rio Grande do Sul, Porto Alegre, Brasil.

Schiffer, M. B. e J. Skibo. 1997. The explanation of artifact variability. American Antiquity 62(1): 27-50.

Scientia Consultoria Científica. 2008. Relatório Final: Projeto de salvamento dos sítios arqueológicos localizados na área diretamente afetada da linha de transmissão Tucuruí/PA - Presidente Dutra/MA $\left(3^{\circ}\right.$ Circuito).

Sheppard, A. O. 1995 [1956]. Ceramics for the Archaeologist. Washington D.C.: Carnegie Institution of Washington Publication.

Silva, F. A. 2000. As tecnologias e seus significados: Um estudo da cerâmica dos Asurini do Xingú e da cestaria dos Kayapó-Xikrin sob uma perspectiva etnoarqueológica. Tese de Doutorado. Programa de Pós-Graduação em Antropologia Social, Universidade de São Paulo, São Paulo, Brasil.

Silveira, M. I., \& D. P. Schaan. 2005. Onde a Amazônia encontra o mar: Estudando os sambaquis do Pará. Revista de Arqueologia 18: 67-79.

Simões, M. F. 1981. Coletores-pescadores do litoral do Salgado (Pará): nota preliminar. Boletim do Museu Paraense Emilio Goedi, Antropologia 78: 1-26.

Viveiros de Castro, E. B. 1986. Araweté: os Deuses Canibais. Rio de Janeiro: Jorge Zahar.

Wagley, C. e E. Galvão. 1961. Os Índios Tenetehara: Uma cultura em transição. Rio de Janeiro: MEC.

Recebido em 28/06/2012.

Aprovado em 15/11/2012. 